\title{
TIPE DATA LARIK (ARRAY)
}

\author{
AdzrielArraffi \\ 185100002 \\ Fakultas Komputer \\ adzrielarraffi.student@umitra.ac.id
}

\begin{abstract}
Array atau larik (dalam Bahasa Indonesia) adalah sebuah tipe data bentukan yang terdiri dari sejumlah komponen dengan tipe yang sama.

Array adalahstruktur data yang menyimpan data-data bertipesamadalamurutantertentu. Array dapatdianalogikansebagaisebuahloker yang memilikisederetankotakpenyimpananyangdiberinomorberurutan. Data-data dalam array disebutelemen array.Dengan array setiapelemenbisadiakseslangsungmelaluiindeksnya, berlebihan lain dari array adalahkitabisamemakaisejumlah -ariabledengannama yang samaasalkan variable tersebutdalamindeks yang berbeda.
\end{abstract}

Kata Kunci : Tipe data larik (array) 


\section{A. PENDAHULUAN}

Latar Belakang Dalam mata kuliah Struktur Data, terdapat materi Array yang menuntut mahasiswa agar dapat memahami array itu sendiri yang nantinya menjadi bekal awal dalam perkuliahan Struktur Data. Array merupakan komponen yang sangat penting dipelajari bagi mahasiswa $\mathrm{S} 1$ Pendidikan Sistem Informasi dan Teknik Informatika. Karena array merupakan materi dasar yang harus dimiliki seorang programmer nantinya. Merupakan pengetahuan dasar yang harus dimiliki untuk memahami pengaplikasian Sistem Informasi dan Teknik Informatika itu sendiri. Oleh karena itu maka disusunnya makalah ini untuk membantu mahasiswa dalam memahami Array. 1. Tujuan Penggunaan Array Tujuan penggunaan array adalah sebagai wadah berkumpulnya nilai-nilai yang bertipe berbeda atau untuk menyimpan berbagai jenis data seperti integer, float, char, dan lain-lain, agar menjadi satu kesatuan,sehingga mempermudah pengelompokan nilai-nilai dan dalam penulisan script menjadi script yang terstruktur dan rapi. Dalam beberapa kasus kombinasi penggunaan array dan looping dapat mempersingkat proses entri data pada $\mathrm{C}++$ Tujuan Pembelajaran Setelah mempelajari materi array mahasiswa diharapkan dapat : a. Memahami definisi array itu sendiri.b. Memahami penggunaan array dalam program yang di buat dalam Algoritma dan Struktur Data. c. Memahami penerapan secara benar dalam penguasaan materi array itu sendiri. 2. Batasan Masalah a.
Pengertian Array. b. Jenis jenis Array. c. Contoh dari jenis Array 1 dimensi.

\section{B. PEMBAHASAN / STUDI KASUS}

Array adalahstruktur data yang menyimpan data-data bertipesamadalamurutantertentu. Array dapatdianalogikansebagaisebuahloker yang memilikisederetankotakpenyimpanan yang diberinomorberurutan.Data-data dalam array disebutelemen array.Dengan array setiapelemenbisadiakseslangsungmelal uiindeksnya.Kelebihan lain dari array adalahkitabisamemakaisejumlah

variable dengannama yang samaasalkan variable tersebutdalamindeks yang berbeda. 1 . KarakteristikArray

:Mepunyaibatasandaripemesananaloka simemori (bersifatstatis) Mempunyaitipe data sama (bersifathomogen)

Dapatdiaksessecaraacak. 2. DeklarasiArray : Ada tigahal yang harus di ketahuidalammendeklarasikan array, yaitu : Type data array Nama variable array Subkrip / index array.

5 Contohdeklarasidari array adalahsebagaiberikut :int $\mathrm{A}[5]$; artinyavariabel A adalahkumpulan data sebanyak 5 bilanganbertipe integer. 3. JenisArray : a. Array SatuDimensi Array satudimensiyaitukumpulanelemenelemenidentik yang hanyaterdiridarisatubarisatauhanyasatu kolomalamatpenyimpanan data 
(indeks).

Elemenelementersebutmemilikitipe data yang sama, tetapiisidarielementersebutbolehberbed a. Bentukumum :Tipe_datanamaarray[n] $=\{$ elemen0, elemen1, elemen2,..,n $\} ; \mathrm{n}=$ jumlahelemenContohpengaksesan Array

Menggunakanvariabelpenampung data : char huruf; huruf = alfabet[0]; (variabelhurufberisi data element array index ke-0 dari array alfabet, yaitu a). Menggunakanprintf :printf( \%c, alfabet[0]); (akanmencetakhuruf a kelayar). Contoh program (2) Pengaksesan data menggunakanprintf 32 Contoh Program

Deklarasisekaligusinisialisasi, danpengaksesan data menggunakankombinasiprintfdanperul angan 33 Contoh Program (4) Ilustrasi Array 1 Dimensi char indeks value alamat 21da 21db 21dc 21dd 21de $21 \mathrm{df} \quad 21 \mathrm{e} 0 \quad 21 \mathrm{e} 1 \quad \% \mathrm{x}$ adalahhexadesimalcontohpadaprogam :intukur[5] $=\{39, \quad, 38,40\}$; intadalahtipe data yang berupabilanganbulat.

Ukuradalahnamavariabel array. [5] adalahukuranuntukmenyatakanjumlah maksimalelemen array. $\{.$. adalahtempatpemberiannilai/elemen array. b. Array DuaDimensi Array duadimensiseringdigambarkansebagais ebuahmatriks, merupakanperluasandari array satudimensi. Jika array satudimensihanyaterdiridarisebuahbari sdanbeberapakolom

6 elemen, maka array duadimensiterdiridaribeberapabarisdan beberapakolomelemenbertipesamasehi nggadapatdigambarkansebagaiberikut : Bentukumum : Tipe_datanamaarray $[\mathrm{m}][\mathrm{n}]=\{\{\mathrm{a}, \mathrm{b}, \mathrm{z}\},\{1,2,, \mathrm{n}-1\}\} ; \mathrm{m}=$ banyaknyabaris $\mathrm{n}=$ banyaknyakolomcontoh : int lulus[4][3]; Nilai 4 untukmenyatakanbanyaknyabarisdan 3 untukmenyatakanbanyaknyakolom.

Pendeklarasian array duadimensihampirsamadenganpendek1 arasian array satudimensi, kecualibahwa array duadimensiterdapatduajumlahelemen yang

terdapatdikurungkurungsikudankeduan yabolehtidaksama. Elemen array duadimensidiaksesdenganmenuliskank eduaindekselemennyadalamkurung.c.

Array MultiDimensi Array iniseperti array dimensiduatetapidapatmemilikiukuran yang lebihbesar. Sebenarnya array dimensibanyakinitidakterlaluseringdig unakan, tetapisewaktuwaktukalaudimensi yang dibutuhkanbanyak, maka array inisangatmemegangperanan yang penting.Bentukumumpendeklarasian array multidimensi :Tipe_datanamaarray[ukuran1][ukuran 2] [ukurann]; Sebagaicontoh : intdata_huruf[2][8][8] contoh di atasmerupakanpendeklarasian array data_hurufsebagai array berdimensitiga. 4 . Contohkasusdarijenis- jenisArray : Di sinisayahanyamenunjukanhasil coding dari array satudimensisajakarnahanyaituyg di minta : a. Array BerdimensiSatu. Berikutiniadalahcontoh program yang memberikaninisialisasiterhadap array berdimensisatu :

7 Input : Output : Input : Output : 
8 Input : Output : 5. Keunggulan Dan Kelemahan Array : Keunggulan array adalahsebagaiberikut : 1. Array sangatcocokuntukpengaksesanacak.

Sembarangelemen di array dapatdiacusecaralangsungtanpamelalui elemen-elemen lain. 2. Jikaberada di suatulokasielemen,

makasangatmudahmenelusurikeelemen -elementetangga,

baikelemenpendahuluatauelemenpener

us 33 . Jikaelemen-elemen array adalahnilai-

nilaiindependendanseluruhnyaharusterj aga,makapenggunaanpenyimpanannya sangatefisien. Kelemahan array adalahsebagaiberikut : Array mempunyaifleksibilitasrendah, sehinggatidakcocokuntukberbagaiaplik asikarena array mempunyaibatasansebagaiberikut : 1 . Array harusbertipehomogen. Kita tidakdapatmempunyai array dimanasatuelemenadalahkarakter, elemen lain bilangan, danelemen lain adalahtipe-tipe lain. 2. Kebanyakanbahasapemrogramanmeng implementasikan array statik yang sulitdiubahukurannya di waktueksekusi.

Bilapenambahandanpenguranganterjad iterus-menerus, makarepresentasistatisTidakefisiendala mpenggunaanmemori

9

MenyiakanbanyakwaktukomputasiPad asuatuaplikasi,

representasistatistidakdimungkinkan.B ilapenambahandanpenguranganterjadit erusmenerus, makarepresentasistatis (array): Tidakefisiendalampenggunaan memory

MenyiakanbanyakwaktukomputasiPad asuatuaplikasi, representasistatistidak di mungkinkan.

\section{ID SECURITY QWTD4452377-ASP-5244107}

\section{KESIMPULAN}

Array merupakan kumpulan tipe data dalam suatu program. - Array memiliki suatu fungsi sebagai wadah berkumpulnya tipe data yang sama namun dengan elemen yang berbeda. Array memiliki 3 jenis yang dibedakan menjadi : array berdimensi satu, array berdimensi dua, array berdimensi tiga(multi). - Array sering digunakan bersama dengan looping untuk mempercepat proses pengentrian data Penggunaan array berfungsi agar lebih mudah dalam pengelompokkan dan penstrukturan data.

\section{E. DISKUSI}

\section{Saya bersama teman saya mendiskusikan hasil dari materi ini dengan baik.}

Saya : Apakah materi saya dapat membantu anda?

Zalmi:Iya materi ini sangat membantu saya dalam proses belajar memahami tipe data larik

Zalmi:Apakah artikel ini pantas untuk dipublikasikan?

Saya : Tentu saja pantas, karna ini sangat membantu proses pembelajaran 
dan bahasanya pun mudah dipahami dan dimengerti

\section{F. REFERENCE}

[1] O. M. Febriani and A. S. Putra, "Sistem Informasi Monitoring Inventori Barang Pada Balai Riset Standardisasi Industri Bandar Lampung," J. Inform., vol. 13, no. 1, pp. 90-98, 2014.

[2] A. S. Putra, "Paperplain: Execution Fundamental Create Application With Borland Delphi 7.0 University Of Mitra Indonesia," 2018.

[3] A. S. Putra, "2018 Artikel Struktur Data, Audit Dan Jaringan Komputer," 2018.

[4] A. S. Putra, "ALIAS MANAGER USED IN DATABASE DESKTOP STUDI CASE DB DEMOS."

[5] A. S. Putra, "COMPREHENSIVE SET OF PROFESSIONAL FOR DISTRIBUTE COMPUTING."

[6] A. S. Putra, "DATA ORIENTED RECOGNITION IN BORLAND DELPHI 7.0."

[7] A. S. Putra, "EMBARCADERO DELPHI XE 2 IN GPUPOWERED FIREMONKEY APPLICATION."

[8] A. S. Putra, "HAK ATAS KEKAYAAN INTELEKTUAL DALAM DUNIA TEKNOLOGY BERBASIS REVOLUSI INDUSTRI 4.0."

[9] A. S. Putra, "IMPLEMENTASI PERATURAN

PERUNDANGAN UU. NO 31 TAHUN 2000 TENTANG
DESAIN INDUSTRI BERBASIS INFORMATION TECHNOLOGY."

[10] A. S. Putra, "IMPLEMENTATION OF PARADOX DBASE."

[11] A. S. Putra, "IMPLEMENTATION OF TRADE SECRET CASE STUDY SAMSUNG MOBILE PHONE."

[12] A. S. Putra, "IMPLEMENTATION

PATENT FOR APPLICATION WEB BASED CASE STUDI WWW. PUBLIKLAMPUNG. COM."

[13] A. S. Putra, "IMPLEMENTATION SYSTEM FIRST TO INVENT IN DIGITALLY INDUSTRY."

[14] A. S. Putra, "MANUAL REPORT \& INTEGRATED DEVELOPMENT

ENVIRONMENT BORLAND DELPHI 7.0."

[15] A. S. Putra, "PATENT AS RELEVAN SUPPORT RESEARCH."

[16] A. S. Putra, "PATENT FOR RESEARCH STUDY CASE OF APPLE. Inc."

[17] A. S. Putra, "PATENT PROTECTION FOR APPLICATION INVENT."

[18] A. S. Putra, "QUICK REPORT IN PROPERTY PROGRAMMING."

[19] A. S. Putra, "REVIEW CIRCUIT LAYOUT COMPONENT

REQUIREMENT ON ASUS NOTEBOOK."

[20] A. S. Putra, "REVIEW TRADEMARK PATENT FOR 
INDUSTRIAL TECHNOLOGY BASED 4.0."

[21] A. S. Putra, "TOOLBAR COMPONENT PALLETTE IN OBJECT ORIENTED PROGRAMMING."

[22] A. S. Putra, "WORKING DIRECTORY SET FOR PARADOX 7."

[23] A. S. Putra, "ZQUERY CONNECTION

IMPLEMENTED

PROGRAMMING

STUDI

CASE PT. BANK BCA Tbk."

[24] A. S. Putra, D. R. Aryanti, and I. Hartati, "Metode SAW (Simple Additive Weighting) sebagai Sistem Pendukung Keputusan Guru Berprestasi (Studi Kasus: SMK Global Surya)," in Prosiding Seminar Nasional Darmajaya, 2018, vol. 1, no. 1, pp. 85-97.

[25] A. S. Putra and O. M. Febriani, "Knowledge Management Online Application in PDAM Lampung Province," in Prosiding International conference on Information Technology and Business (ICITB), 2018, pp. 181-187.

[26] A. S. Putra, O. M. Febriani, and B. Bachry, "Implementasi Genetic Fuzzy System Untuk Mengidentifikasi Hasil Curian Kendaraan Bermotor Di Polda Lampung," SIMADA (Jurnal Sist. Inf. dan Manaj. Basis Data), vol. 1, no. 1, pp. 21-30, 2018.

[27] A. S. Putra, H. Sukri, and K. Zuhri, "Sistem Monitoring Realtime Jaringan Irigasi Desa (JIDES) Dengan Konsep Jaringan Sensor Nirkabel,"
IJEIS (Indonesian J. Electron. Instrum. Syst., vol. 8, no. 2, pp. 221-232.

[28] D. P. Sari, O. M. Febriani, and A. S. Putra, "Perancangan Sistem Informasi SDM Berprestasi pada SD Global Surya," in Prosiding Seminar Nasional Darmajaya, 2018, vol. 1, no. 1, pp. 289-294. 